\title{
UN EJEMPLO DE TEATRO MUSICAL POPULAR NOVOHISPANO DEL SIGLO XVIII

\author{
EL CASO DE LA TONADILLA A SOLO LOS RETRATOS YRONICOS
}

THE NEW SPAIN POPULAR MUSIC THEATER

THE CASE OF THE ONE-PLAYER TONADILLA A LOS RETRATOS YRONICOS

\author{
Rey Fernando Vera García \\ Universidad Nacional Autónoma de México \\ Posgrado en Letras \\ rfernandovera@gmail.com
}

\section{Resumen}

La tonadilla fue uno de los géneros breves más gustados durante el siglo Xvin en Nueva España. Listas de avalúos y aperos del Coliseo de México muestran una cantidad abrumadora de estas piezas lírico/musicales. Mayoritariamente eran de origen peninsular; sin embargo, algunas de ellas fueron compuestas en el territorio novohispano. El propósito de este trabajo es presentar la transcripción de la letra de una de estas obras: Los retratos irónicos.

Palabras clave: teatro mexicano, teatro del siglo XvıII, tonadilla, géneros breves, teatro musical.

\begin{abstract}
In 18th century New Spain the tonadilla was one of the music theater genres most favored by audiences. Inventories of the Coliseo theater in Mexico City reveal the existence of a large number of musical pieces of this sort. Although the majority of them came from Spain, some were composed in New Spain as well. A transcription of the lyrics for Los retratos irónicos, a solo tonadilla of Mexican origin, is offered here.
\end{abstract}

\section{Keywords}

Mexican theater, eighteenth century theater, tonadilla, short plays, musical theater.

\section{Información del artículo}

Recibido: 21 de marzo de 2018.

Aceptado: 23 de mayo de 2019.

DOI: 10.22201/iih.24486922e.2019.61.64000 
La comprensión del fenómeno teatral del siglo XviII novohispano estaría incompleta si no reconocemos, desde un inicio, que se trataba de un espectáculo que incluía música básicamente en todos sus niveles y en todas sus manifestaciones. Esto, sin lugar a dudas, es decir bastante, pues implicaría reconocer que incluso en aspectos formales, no sólo la configuración de las jornadas de teatro, sino las mismas obras, sobre todo las de géneros breves como el sainete, la tonadilla, el entremés y los bailes, largamente vilipendiados por una supuesta estrechez poética, no carecían de mérito alguno, sino antes bien se estarían evaluando actualmente sin contemplar una de sus principales partes constitutivas.

Precisamente, la tonadilla escénica fue uno de los géneros teatrales más importantes del siglo XVIII hispánico, y su principal característica fue la música. Se iba al teatro a escuchar tonadillas, mismas que se replicaban después en las calles con acompañamiento de vihuela o guitarra. Existe una firme creencia de que muchos de los sones tradicionales mexicanos tienen una afinidad con diversas tonadillas dieciochescas (Vera, 2018).

Formalmente la tonadilla era un género de música teatral breve. Constaba de tres partes: entable, coplas y seguidillas. La primera de ellas funcionaba como una introducción en la que se explicaba de qué trataría toda la pieza; las coplas correspondían al desarrollo, y conclusión de la pieza; finalmente las seguidillas eran la parte final, cantada y bailada, que no necesariamente debía guardar relación con el resto de la pieza. ${ }^{1}$

La tonadilla que presentamos ahora, Los retratos irónicos es presumiblemente de auténtico cuño novohispano. El original es una copia de principios del siglo xıx cercana a 1808, pero una lista de las piezas cantadas en el Coliseo durante el año de 1793, indica que la tonadilla fue representada el día 12 de marzo junto con el sainete El desdén. En la misma lista, además, se mencionan otras obras propias del territorio como el Pan de manteca que fue bailado y cantado por dos actores del Coliseo cuyos nombres eran Mariano y Vicenta. Sin embargo, el texto que presento tuvo quizá cierto alcance, pues se cantó en 1806 dentro de una función regular en el

${ }^{1}$ Cualquier estudio sobre la tonadilla debería comenzar con el reconocimiento del musicólogo catalán José Subirá Puig, quien entre 1928 a 1932 publicó tres monumentales volúmenes sobre el tema, donde estableció la forma y la estructura de la tonadilla. Cfr. La tonadilla escénica. Madrid: Tipografía de Archivos. Al año siguiente, 1933, Subirá publicaría un nuevo tomo, La tonadilla escénica, sus obras y sus autores, en el que rescataría tonadillas inéditas. No obstante el valor de esta empresa, es importante también reconocer las nuevas valoraciones y las atentas revisiones que se han hecho actualmente por las doctoras Elisabeth Le Guin, Aurèlia Pessarrodona i Pérez y Montserrat Capelán. Véase bibliografía. 
Coliseo de La Habana, por lo que otras copias debieron haber existido desde su estreno mexicano de $1793 .^{2}$ Hasta ahora me es desconocido otro testimonio manuscrito o impreso de la obra, de modo tal que me es lícito considerar inédito el documento que presento a continuación. ${ }^{3}$

El manuscrito original fue hallado en la caja 6683, expediente 117, del ramo Indiferente Virreinal del AGN. Es probable que los papeles que componen dicho expediente provengan todos del Coliseo de México o de alguien involucrado directamente con el teatro, quizá algún actor. El manuscrito presenta marcas y otras señales que resaltan pasajes y sugieren indicaciones, por lo que estaríamos ante una copia de alguien que ejecutó la pieza. Junto a esta tonadilla, se hayan además, otras dos canciones, una cuyo tema es la invasión francesa a España y posterior captura de Fernando VII y otra que es una lamentación en voz de un personaje infernal, probablemente extracto de alguna comedia de igual cuño novohispano. ${ }^{4}$

Como era costumbre en los manuscritos de tonadillas conservados, mediante números delante de los versos se indican las repeticiones que el cantante (casi siempre una actriz) debía hacer al momento de ejecutarla con el acompañamiento musical. Siguiendo estas indicaciones numéricas, la tonadilla a solo Los retratos irónicos, se compone de 168 versos que se estructuran en coplas de seguidilla, es decir, versos alternados de 7 u 8 sílabas con otros de 5. Así pues, la métrica de los versos, aunque inexacta en muchos momentos, es notablemente regular y se ciñe bastante bien a los patrones propios de su género, lo que sugiere que cualquier ripio en la versificación se vería arreglado una vez que fuera interpretada con el acompañamiento musical.

Como tonadilla, posee las tres partes requeridas, un entable en el que la voz lírica anuncia el tema y el alcance de la obra; coplas en las que desarrolla la pieza, y unas seguidillas presumiblemente bailables que rematan todo y que no necesariamente se ajustaron con el contenido de la obra. Además de esto, tiene dos pasajes de boleras y un recitado. Las primeras correspondían necesariamente a una parte bailada y el recitado era un descanso previo a las coplas para crear un contraste sonoro con éstas.

El tono es paródico y tenía como intención denostar y hacer mofa de varios estereotipos de la sociedad novohispana de su tiempo. Visto bajo las normas morales de la época, seguramente resultó de notable "mal gusto" y

\footnotetext{
${ }^{2}$ Teatro (1806). Cfr. Boudet (2017, p. 31).

${ }^{3}$ Archivo Histórico del InAH, Hospital de Naturales, t. 104, f. 56.

${ }^{4}$ Ambas obras están siendo editadas por el autor de las presentes líneas.
} 
"escandalosa" del todo. El texto si bien no revela, como otras canciones de la época, mofas y ofensas abiertas a los tipos aludidos, pues no existe una sola descripción de ellos, luce, sin embargo, un tono socarrón e irreverente durante toda la pieza.

La lectura atenta del manuscrito admite la posibilidad de que quien la ejecutara haya llevado en escena los retratos de los tipos aludidos. No era infrecuente esta técnica en el Coliseo de México, en el que habitualmente se recurría a cuadros y pinturas de personajes diversos, entre ellos, los monarcas, los virreyes y los arzobispos, con la finalidad de hacerlos presentes simbólicamente en el espectáculo. Los avalúos del Coliseo dan cuenta del precio que se fincaba por esos cuadros, mismos que uno ve realizados, que pasaban a engrosar los aperos de la compañía teatral.

La tonadilla misma es un documento valioso sobre la sociedad novohispana de finales del xviır. Cada uno de los "retratos" aportaría valiosos datos sobre la recepción y la concepción que la sociedad tenía de los individuos mencionados. La tonadilla revela de este modo, bastante de la idiosincrasia regente en su momento.

Respecto de la edición, presento el texto tal cual fue encontrado, esto es conservando sus particularidades ortográficas y léxicas. Mi objetivo es realizar una transcripción lo más fiel posible. En cuanto a las repeticiones que el manuscrito señala, éstas se han replicado con los mismos números, salvo en aquellos casos que indicaban retahíla de versos o repetición alternada, en ese caso el símbolo empleado es $>2$ y se coloca delante del último verso en el que aplica. Las marcas de barras cruzadas que tiene el manuscrito y que transcribo con el signo \# significaban hacer énfasis y sobresalir por encima de los elementos del escenario, esto es dirigirse al proscenio, parte más iluminada del teatro. El manuscrito posee tiradas de versos encerrados en recuadros, lo que significaba su supresión al llevarse a escena. Estos versos elididos los transcribo subrayados. Entre corchetes se han hecho los añadidos lógicos necesarios. La letrilla de esta tonadilla debía en el mejor de los casos, adaptarse a la tradición estrófica del género, esto es, mediante coplas de seguidilla, versos de 7 u 8 sílabas alternados con versos de 5, en los que los impares son libres y los pares tienen rima asonante. Los retratos irónicos, sin embargo, es de manufactura deficiente y su métrica es pobre; revela por lo demás que fue un apunte de teatro hecho con rapidez y descuido; es decir, una copia que hacían las personas del teatro para ensayar una obra que, de cualquier modo, conocían bien. Sin embargo, cumpliendo con el propósito de la difusión de textos sobre 
teatro novohispano del XviII, consideramos que no carece de pertinencia la transcripción que presentamos aquí. ${ }^{5}$

\section{LOS RETRATOS YRONICOS \\ Tonadilla a solo nominada}

[Entable]

Chito señores si quieren ver (2)

si quieren ver (2)

varios caprichos de mi pincel (2)

de mi pincel. (2)

A mil fantasmas

he dado ver $>2$

he dado ver.

Como toditos

aqui vereis $>2$

aqui vereis (6)

escuchad

atended $>2$

oid, oid, oid.

\section{Recitado}

La malicia del mundo

en la pintura

fue mi savia maestra

me enseño a bosquejar

varias constumbres

con sus colores doy alma

a las cosas aereas

${ }^{5}$ Justo es decir que actualmente preparo una edición crítica de este texto dentro del Proyecto PAPIME Lengua, Lingüística y Teatro en la Nueva España a cargo de la doctora Aurora González. Dicha edición no se contrapone de ninguna manera con lo que aquí presentamos, antes bien lo complementa. 
siguiendo siempre el arte

que mi zelo aprendió

en tan buena escuela

oid, oid, y en estas coplas

copias vivas vereis de cosas muertas.

\section{Coplas}

para retratar al vivo

la conciencia (2)

ya se ve (2)

como murió hace dias (2)

he pintado a un mercader (2)

hize muy bien (2)

Para retratar al vivo

a la verdad, a la verdad

ya se vee (2)

como murio ya hace dias (2)

a un sastre aqui retraté (2)

hize muy bien (2)

para retratár al vivo

la firmeza (2)

ya se vee (2)

como murió ya hace dias (2)

he pintado a una muger (2)

hice muy bien (2)

Boleras

Desta manera

varios retratos he hecho

retratos he hecho

de cosas que faltaron

si es que existieron. $>2$

Tengan cuydado

que faltan

otros retratos $>2$ 
Coplas

Para retratar al vivo

la honestidad (2)

ya se vee (2)

una niña destos tiempos (2)

perfectamente copié (2)

hize muy bien. (2)

Para retratar al vivo

la integridad (2)

ya se vee (2)

como murio ya haze dias (2)

a un escrivano pinté (2)

hize muy bien. (2)

Para retratar al vivo

la madurés (2) o

ya se vee (2)

como murió ya haze dias (2)

a un petimetre copié (2)

hize muy bien. (2)

Boleras

De varios personajes

que ya murieron (2)

voy dejando retratos

muy verdaderos $>2$

mas por si canso

con unas seguidillas

el tema acavo. $>2$

Seguidillas

Quando mi tonadilla (2)

salgo a cantaros (2)

el corazon se agita 


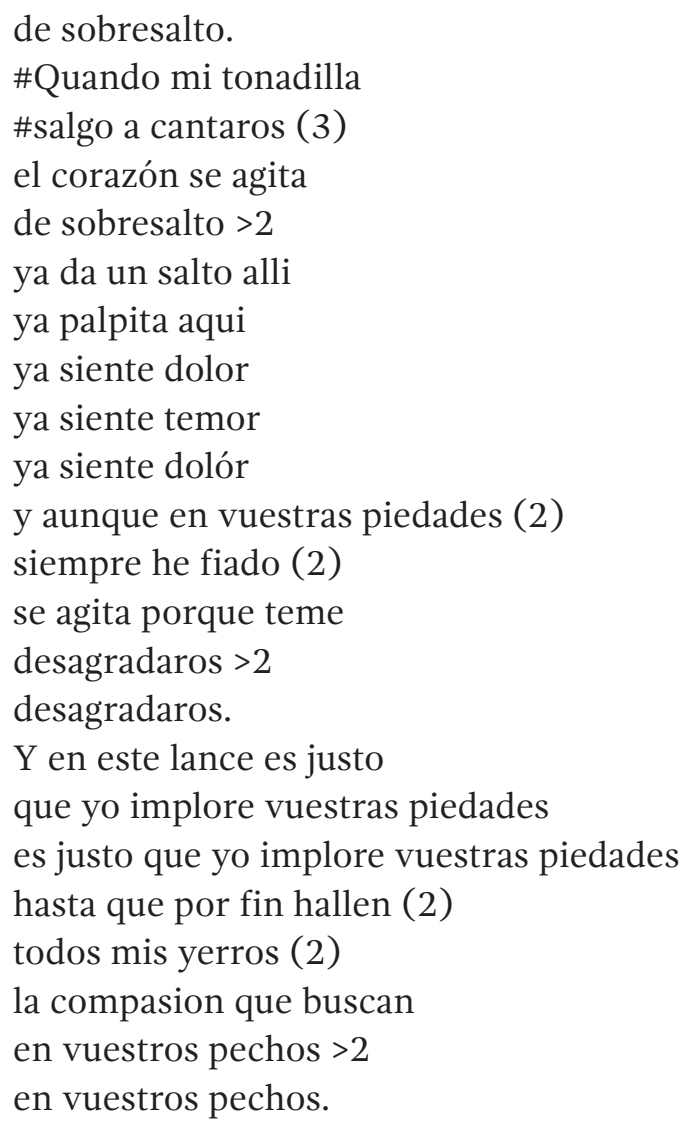

Fin

\section{FUENTES}

Fuentes primarias

Archivo General de la Nación (AGN), Indiferente Virreinal, caja 6683, exp. 117. Archivo Histórico del INAH, Hospital de Naturales, t. 104, f. 56.

Teatro (1806).

El Aviso (La Habana, Cuba), 240. 


\section{Bibliografía}

Boudet, R. I. (2017). Cuba: actores del XIX. Santa Mónica, California: Ediciones de la Flecha.

CAPELÁn FERnÁndez, M. (2015). Las reformas borbónicas y la música venezolana de finales de la Colonia (1760-1821): el villancico, la tonadilla escénica y la canción patriótica. Volumen 1. Tesis doctoral. Santiago de Compostela: Universidad de Santiago de Compostela, Facultad de Geografía e Historia, Departamento de Historia del Arte, Programa Música en la España Contemporánea.

(2017). La tonadilla escénica en Venezuela o el proceso de criollización de un género hispano. Anuario Musical, 72, 137-152.

LE Guin, E. (2014). The Tonadilla in Performance. Lyric Comedy in Enlightenment Spain. Berkeley: University of California Press.

Pessarrodona i Pérez, A. (2006). Catálogo descriptivo de libretos de tonadillas impresos en Barcelona en el siglo XVIII. Recerca Musicològica, XVI, 17-63.

(2015). Ritmos de tonadilla: algunas consideraciones a partir de la obra conservada de Jacinto Valledor. Cuadernos de Música Iberoamericana, 28, 87-114.

(2015). La tonadilla hoy. Materia: Revista Internacional D'Art, 9, 179-186.

Vera García, R. F. (2018). Primer acercamiento al estudio de la tonadilla escénica en la Nueva España durante el siglo Xviır: Edición de la letra de la tonadilla a solo: Ya tienes México Grande, sobre la crítica que se hace de las cosas de teatro. Revista de Literaturas Populares, XVIII-1, 158-190.

\section{SOBRE EL AUTOR}

Candidato a doctor en Letras por la UNAM, grado que pretende obtener con una tesis sobre el teatro popular novohispano del siglo XviII. Es maestro en Letras, grado que obtuvo con una disertación acerca del teatro para marionetas del siglo XVIII al xx. Especialista en Literatura Mexicana del siglo xx por la Universidad Autónoma Metropolitana-Azcapotzalco, se licenció en Letras Hispánicas por la Facultad de Filosofía y Letras de la UNAM. Actualmente forma parte del proyecto Lengua, Literatura y Teatro en Nueva España, en el que está editando obras de teatro popular del periodo novohispano. Sus líneas de investigación son el teatro popular novohispano de finales del siglo xviII, la historia de las marionetas en México y la relación entre historia y literatura. 